sequence, the disease in the infants took on such a mild form that it did not manifest itself until many years later.

Col. Harrison had spoken about the number of men who would be needed to do all the Wassermann tests required, but provision should have been made for this. The suggestion had not been sprung upon the country. In 1928, this Society had made the suggestion that routine antenatal testing and treatment should be carried out, and it was obvious then that, if the Government acted upon the suggestion, a number of additional serologists would be required. Health visitors should be trained to educate the mothers, and they would play a great part in the future of this work. If the mothers were properly educated by tactful health visitors, he felt sure that few mothers would raise any objection to being tested.

He hoped the discussion would arouse the profession. The trouble was that in this Society we were preaching to the converted; we wanted to teach those who did not know what can be achieved in this matter. Even if only a few thousand children were saved every year from premature death, from blindness, or from an asylum, it would be worth while, and no effort should be spared to attain this end.

\title{
THE TREND OF ANTISYPHILITIC TREATMENT
}

\section{By DAVID ERSKINE, M.D., D.P.H. \\ Medical Officer, Venereal Diseases and Dermatology Departments, Guy's Hospital; Medical Officer in charge of Venereal Diseases Clinic, Kent and Canterbury Hospital}

Inadequate treatment of recent syphilis in the early days of salvarsan and neosalvarsan is responsible for many of the patients with destructive tertiary lesions and those with congenital syphilis who are under treatment today. Experience of relapses has gradually indicated the necessity for the prolongation of continuous and combined treatment with arsphenamine and bismuth after the outward signs of syphilitic lesions have disappeared. As a result of this experience a high standard of cure can be anticipated with the present-day routine measures.

\section{Intolerance to standard treatments}

Unfortunately the regular and prolonged treatment which is necessary in well established schemes demands a high degree of cooperation by the individual patient and many default before they have received an adequate amount of treatment. Failures are also caused indirectly by intolerance to treatment; the toxic effects of the arsenical and bismuth compounds are not confined to the Treponema pallidum but extend to the host in a proportion of cases ; the incidence of these toxic manifestations has risen considerably in some centres during recent years and often interferes with the full treatment of a patient. To overcome this difficulty and in a search for a more effective control of the disease, certain intensive types of treatment are being investigated.

Many theories have been advanced to explain intolerance to chemotherapy and alternative drugs have been advocated on inconclusive evidence. Treatment schemes of modified intensity have been adopted by some authorities in an attempt to reduce the toxic effects and have perhaps jeopardized the standard of cure without ensuring a reduction of intolerance. A standard of treatment which is capable of giving a high rate of cure having been adopted, it is agreed that we are probably over-treating a majority of patients, a minority of whom might have been cured with only a few injections. But twenty years is a long time to wait for evidence of failure and the destructive lesions which may occur at the end of that period are tragedies which should be avoided. Investigations suggest that patients who have not relapsed serologically in five years are probably cured and will not relapse at a later period.

\section{Avoidance of toxic effects}

Having adopted a standard of cure which conforms to the accepted present-day requirements, we should assess the likelihood of the patient tolerating the treatment. Apart from immediate reactions due to individual injections, the toxic effects which most commonly complicate antispecific treatment are jaundice and dermatitis. 
Four methods of avoiding toxic effects.-To avoid these toxic effects we can (1) give adjuvant treatment to avert complications; or (2) modify the standard treatment. We can (3) select alternative compounds and, if necessary, alternative schemes for treatment; or (4) face the possible complication from present routine treatment and improve the methods of relief. But it is essential that we select an effective course of treatment which will give a tolerably good expectation of cure.

\section{Adjuvant treatment}

There is not any conclusive evidence that administration of the various vitamins, glucose or solvents, or adjustment of dietary factors or the general management of a case will favourably influence the toleration of treatment. Apart from pyrexial reactions, it appears that arsenical toleration is directly related to the rate of metabolism and it might, therefore, be feasible to stimulate metabolism during treatment by such means as the concurrent administration of thyroid gland extract. Conversely, excessive metabolism and fatigue are contra-indications and recent evidence obtained from treating patients in the Forces suggests that this may be an important factor in establishing toxic reactions.

\section{Modification of standard treatment}

A section of one of the Forces has been treated by a modified scheme in which several alternate weekly arsenical injections are omitted from the standard course of treatment, bismuth being given each week. The total amount of arsenical compounds thus administered over a period of time is reduced below that internationally accepted as constituting the required intensity of treatment, nevertheless the occurrence of jaundice is not abolished. The fact that fewer complications have occurred cannot be accepted as a justification, since a lower incidence is being experienced by many centres which have not adopted this modified technique. If jaundice is not prevented and some apprehension persists that the proportion of cures may be low, this method cannot be regarded as satisfactory even for those patients who will be under observation for the necessary five-year period.

\section{Use of alternative arsenical compounds}

Arsphenamine was found to be an effective but toxic remedy for syphilis in vivo ; neoarsphenamine was adopted as a suitable alternative remedy because of its high rate of cure and because it was less toxic. The biological assay of the reputable neoarsphenamine compounds by the Medical Research Council has shown that in spite of the difficulties of manufacture a remarkably small variation of toxicity and therapeutic effect occurs, even when batches suspected on clinical grounds have been submitted to close investigation. It is, of course, imperative that the ampoules of neoarsphenamine should not be faulty, that the powder should be selected by colour, and that an ampoule to which air is not heard to enter on opening should be rejected. The solution must be made immediately before injection and the solvent should be fresh sterile doubly-distilled water. With these precautions many untoward so-called reactions from neoarsphenamine can be avoided. One centre recently experienced a high incidence of jaundice from neoarsphenamine, but observation revealed the gross, although innocent, negligence of making up bulk solutions which were used in a busy session even two or three hours after preparation. Arsenoxide has been adopted in an attempt to overcome intolerance ; it was selected because it is the active form to which the arsphenamines are believed to be converted in the body before attaining biological activity against the Spirochaeta pallida and because it is stable and not liable to undergo toxic changes by oxidation.

Arsenoxide (mapharside). - This has been widely used in the United States of America for some years, largely on account of its rapid excretion which makes it a more suitable compound for the intensive so-called five-day treatment. It is available in Great Britain as mapharside and neohalarsine. The evidence on which its efficacy has been recommended should be critically reviewed; opinion is strongly divided on the practical value of the remedy in the prolonged routine 
schemes of treatment and many venereologists find it liable to cause intolerance. This view seems to be confirmed by a recent census of toxicity which, in the doses now being employed, shows that the incidence of jaundice in patients treated with mapharside is certainly not lower than in those treated with any other arsenical remedy. In addition, the rapid excretion of mapharside is an important feature and necessitates the inconvenience of twice-weekly injections and, by comparison with the slowly excreted and cumulative neoarsphenamine, it causes increased anxiety in the management of the patient who attends irregularly.

Comparison between neoarsphenamine and arsenoxide.-The necessity of a controlled comparison of neoarsphenamine with arsenoxide in the treatment of syphilis is widely appreciated. Most investigations carried out so far have been confused by the concomitant use of bismuth which is admittedly a powerful antisyphilitic-remedy. However Longley, Clausen and Tatum (1941) showed that both neoarsphenamine and mapharside were capable of curing syphilis in rabbits but that 7 milligrams of neoarsphenamine per kilogram of body weight was more effective than 3.5 milligrams of mapharsen per kilogram. From this evidence the comparable therapeutic dosage would appear to be at least in the order of $2: 1$. In the experimental intensive five-day treatment, 5 grammes of neoarsphenamine was at first administered, but this was found to give too high an incidence of serious toxic complications ; 1.2 grammes of mapharside was adopted later and gave comparable clinical rates of cure, but Leifer, Chargin and Hyman (1941) found that if the total dose fell below 1.2 grammes, the results of treatment were inferior to those when 4 grammes of neoarsphenamine were used ; the comparable therapeutic dosage therefore appears to be about $4: 1$. In the full course of treatment, the rapid excretion of mapharside and the smaller arsenical content of the effective dosage possibly accounted for the lower toxicity of the drug as compared with neoarsphenamine ; nevertheless, neoarsphenamine showed the more satisfactory rate of cure.

Ross (1943) investigated the comparative value of neoarsphenamine and mapharside in the treatment of early syphilis. In each group treatment was given for thirty-nine days and was supported by bismuth injections with a dosage of 0.75 gramme of neoarsphenamine or 0.1 gramme of mapharside given in two injections each week. Unfortunately, comparison of intolerance was not made, but it was stated that toxic reactions were minimal ; one death occurred during treatment with mapharside. In a group of 150 patients treated with mapharside, only one failed to obtain serological reversal three months after completion of the course; however only twenty-six patients had been observed for a period of one year.

Jones and Maitland (1943) introduced a new conception of antisyphilitic treatment and reported on 100 cases submitted to a modified intensive course of treatment. Using the Kolmer-Wassermann technique, they were able to divide primary syphilis into three serological categories and sub-groups and they claimed that patients with lower blood serum titres could be successfully treated with less than 900 milligrams of mapharside in ten days ; patients showing the higher blood titres were given 1,200 to 1,800 milligrams within a period of fifteen to thirty days. They suggest that the grading of doses in modified intensive treatment according to the severity of the infection as measured by a quantitative Wassermann reaction should reduce the recognized toxic effects of this type of treatment without unfavourably influencing the therapeutic results. They obtained encouraging results but further prolonged observation of their own patients and similar groups of other patients under controlled conditions will be necessary before this new method can safely be assessed.

Davies (1943) has recently published a detailed report on the beneficial therapeutic effects and comparatively low toxicity of arsenoxide (mapharside) which suggests a preference for this drug in the prolonged routine schemes of antisyphilitic treatment. The report covers the period from 1929 to 1941 and very strongly recommends this newer method of treatment. The treatment is based on a therapeutic ratio of nearly $8: 1$, for weight for weight mapharside is 
claimed to be seven and a half times as potent as neoarsphenamine, although the grounds for this ratio are unproven and the ratio is not supported by the experimental evidence quoted above. Two points arise from this report. First, will the therapeutic results of these smaller doses of arsenoxide prove as reliable as a cure over a period of time as those which would be obtained with the experimentally relative doses indicated above? Secondly, the lower comparative doses employed might reasonably be expected to give a lower incidence of toxicity, but this would be of little advantage if the success of the cure were thereby lessened. In this report the spirochaeticidal effects of neoarsphenamine and mapharside are compared. The details of the examination for the presence of $S$. pallida in the chancre transudate during treatment are given and better results are claimed with mapharside than with neoarsphenamine. With mapharside only four chancres out of thirty-seven with positive $S$. pallida findings failed to become negative in twenty-four hours; details are not given of any chancres treated with neoarsphenamine except to say that 159 out of 209 cases were examined and found negative in twenty-four hours. The report does not specify whether the other fifty cases were tested and found positive. In this survey the results obtained by treatment with mapharside as against neoarsphenamine are compared. The results obtained with neoarsphenamine are based on a report by Harrison (1929) which covers the years 1920-6. At that time a less intensive experimental scheme of treatment was employed; this having been found to be inadequate, was abandoned in 1928. The results with mapharside are based on experience in the period 1936-41. Thus, the basis of comparison of therapeutic effects is untenable, apart from the fact that serological reactions are not necessarily criteria of cures. It should also be noted that only 10 per cent of the patients treated with mapharside remained under observation for over one year and there is not any indication of examinations of cerebrospinal fluid in these cases.

For a comparison of the toxicity of neoarsphenamine as against mapharside another time group altogether is adopted and the period 1929-36 is chosen. The incidence of jaundice seems to have been extraordinarily high in the male cases reported and probably greater than at most clinics in Great Britain during those years. Furthermore, it appears that, in the female patients at the clinic during that period jaundice was practically non-existent, hence it is difficult to correlate the incidence of jaundice with the neoarsphenamine compounds. In any case the incidence of jaundice varies from year to year and it is not statistically significant to compare the experience when one drug is used in one seven-year period with the incidence experienced whilst another drug is used during a totally different five-year period. The only tenable comparison is one based on the strict rotation of treatment to alternate patients attending in the same time group. Further, the stage of syphilis is not indicated in the analysis of toxicity, the age factor is dismissed as negligible, although older patients would be expected to have received less intensive treatment; the average dose received per patient is not stated for comparison and, whereas 501 cases of early syphilis are specified in respect of therapeutic effect, the analysis of toxicity covers 1,147 cases treated with mapharside. The incidence of jaundice must be weighted favourably in later years of the 1929-41 period by the preponderance of patients remaining under observation and not still needing active treatment.

In the conclusions of this survey it is stated that "some cases that have had jaundice following neoarsphenamine subsequently tolerate arsenoxide". This is not an important observation, for many patients after recovering from jaundice associated with treatment with neoarsphenamine will again tolerate neoarsphenamine. Before this survey of results can be accepted, the necessary criteria indicated above must be submitted in order to make the analysis statistically significant. It would appear that the investigation of a new series of cases is required and, in places where facilities exist, a statistical analysis of the two compounds based on strict rotation of treatment to alternate patients is indicated, in dosages which enable toxicity and therapeutic effects to be compared over the same period of 
time. It is well recognized that apparent response may result from inadequate chemotherapy ; what is of importance is the ultimate condition of the patients observed during long periods necessary to assess failures.

Dudley (1943) found the incidence of jaundice as high as 40 per cent in the routine treatment of naval personnel with neoarsphenamine and claims without quoting figures that mapharside gives a lower incidence of toxic effects, when used in correspondingly smaller does. It would be interesting to know if this preliminary opinion has been maintained with continued experience. Dudley considers that neoarsphenamine "mixtures" vary in composition but this is not upheld by the Medical Research Council tests referred to above. He dismisses the virus theory of jaundice as unacceptable to clear thinkers who adopt a single simple working hypothesis, and suggests that the toxic neoarsphenamine is selfexplanatory. This factor does not, however, explain all the facts, for one batch is widely distributed and all treatment centres do not experience the same degree of misfortune in regard to toxicity. The simple stable arsenoxide is less susceptible to errors of technique which may be important in a branch of the Forces which does not rely on specialist venereologists for routine treatment, but is the correspondingly smaller dose employed comparable as regards toxicity and, of paramount importance, is it an adequate dose for cure of the disease ?

\section{Conclusions}

Experienced personnel in the Forces have the opportunity of observing comparable groups of patients undergoing treatment with alternate compounds and variable doses and they should have comparative control over the movements of their patients.

Such control and observation unfortunately is not available in the civilian clinics. Until comparable statistics are available, standard schemes of treatment with the proved effective remedies will give a satisfactory degree of cure, although there will be still defaulting of patients and toxicity of drugs as a result of prolonged treatment. Improved education of the public and a tactful approach to patients will reduce the defaulter rate; skilled observation, with appropriate palliative treatment when indicated, will achieve results which will justify the recognized risk of toxicity and the chances of fatalities will be minimized.

We would fail in our duty to patients if we threw away the experience gradually gained in the chemotherapy of syphilis during the past thirty years. Until convincing evidence is forthcoming that these modified treatments will give not only reduced toxicity with comparable therapeutic results but also a cure rate as reliable as can now be promised to the fully cooperative patient, we would be wise to rely upon that experience.

\section{REFERENCES}

Davies, T. A. (1943) J. R. nav. med. Serv., 29, 153.

Dudley, S. F. (1943) J. R. nav. med. Serv., 29, 171.

Harrison, L. W. (1929) Spec. Rep. Ser. med. Res. Coun. Lond. No. 132.

Jones, T. R. L., and Maitland, F. G. (1943) Brit. med. J., 2, 448.

Leifer, W., Chargin, L., and Hyman, H. T. (1941) J. Amer. med. Ass., 117, 1154

Longley, B. J., Clausen, N. M., and Tatum, A. L. (1941) J. Pharmacol., 71, 49.

Ross, A. O. F. (1943) Lancet, 1, 704.

\section{Venereal diseases in Sweden}

In the Swedish Home Service in October, 1943 there was a broadcast about a discussion which took place at the Swedish Public Health Department on the spread of venereal diseases and the possibilities of combating them. Besides the members of this Department and its scientific advisers, the Chiefs of the Medical Staffs of the Army, Navy and Air Force, and several specialists took part. It was pointed out that the situation was causing grave concern and that effective measures must be taken soon; the greatest increase had taken place in the cities, which should receive first attention. It was essential to apply the same principles to venereal diseases as to certain other infectious diseases in which good results had been achieved. The general opinion was that the connexion between social conditions and venereal disease should not be overlooked.-Daily Digest of World Broadcasts. British Broadcasting Corporation. 